\title{
Successful mucosal closure of artificial gastric ulcer with twin grasping forceps and endoclips after endoscopic submucosal dissection
}

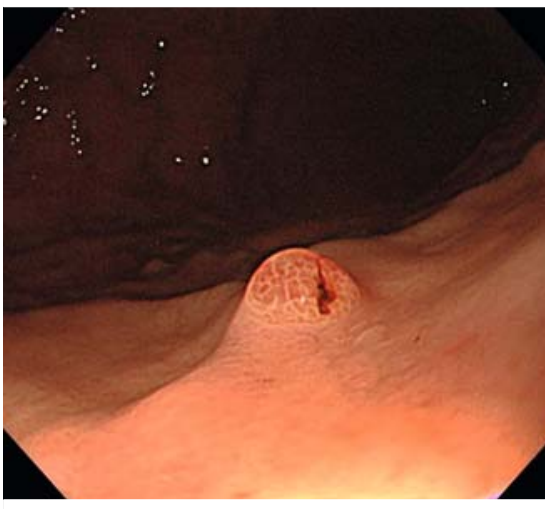

- Fig. 1 Early gastric cancer (tumor diameter $3 \mathrm{~mm}$ ) located in the greater curvature of the upper body of the stomach.

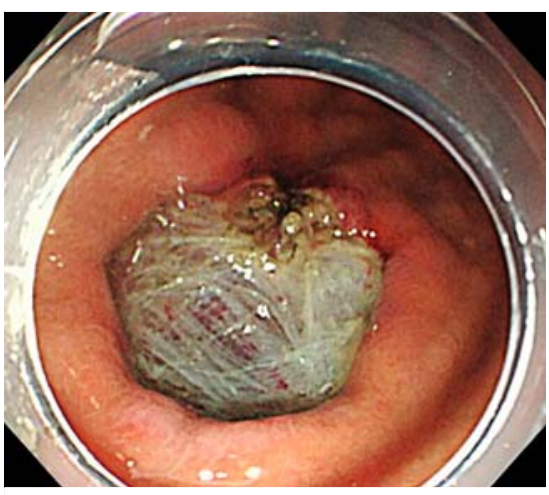

- Fig. 2 Endoscopic submucosal dissection was performed and resulted in a mucosal defect (diameter $20 \mathrm{~mm}$ ).

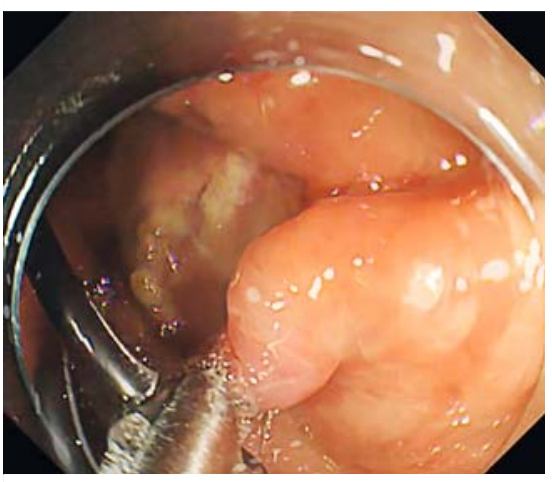

- Fig. 3 The two arms of the Twin Grasper were used to grasp and appose both edges of the artificial ulcer.

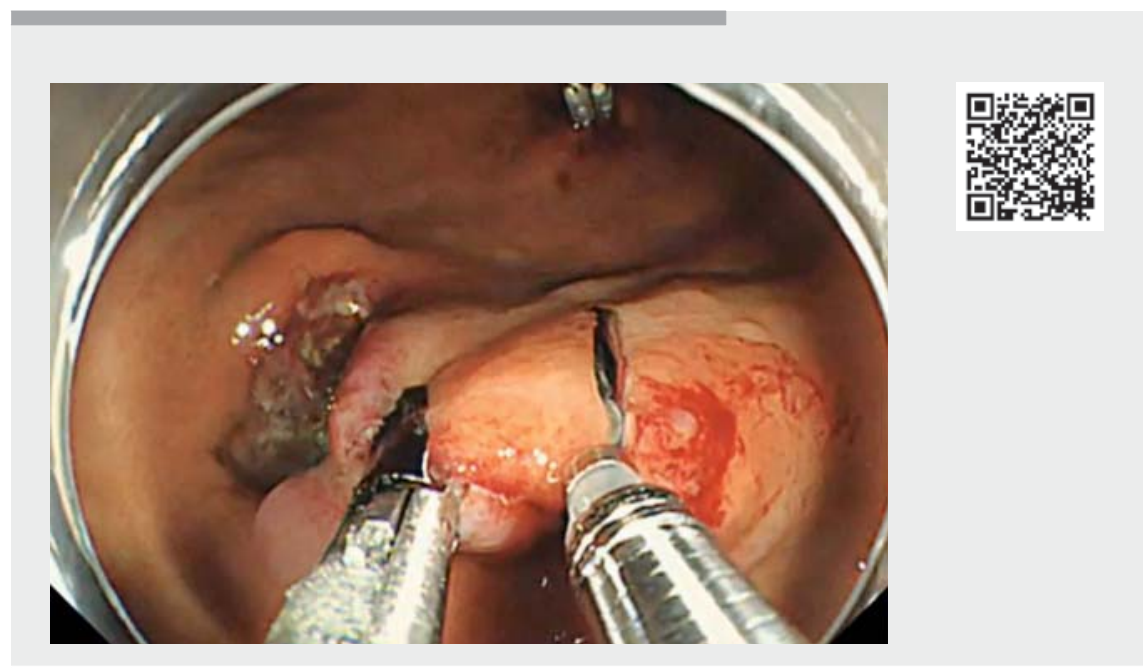

$\checkmark$ Video 1 Twin grasping forceps and endoclips used for successful mucosal closure of artificial gastric ulcer after endoscopic submucosal dissection.

The risk of postoperative adverse events following endoscopic resection can be reduced through endoscopic closure of the artificial gastric ulcer [1], but it is not easy owing to the gastric wall thickness and hardness. There are several methods for closing ulcers induced by gastric endoscopic submucosal dissection (ESD) [2-5]. Here, we describe the successful simple closure of a post-gastric ESD artificial ulcer using twin grasping forceps (Twin Grasper; Ovesco Endoscopy AG, Tubingen, Germany) and endoclips (EZ clip; Olympus, Tokyo, Japan).

An 89-year-old man with early gastric cancer (upper part of the gastric greater curvature) underwent ESD that resulted in a mucosal defect (artificial gastric ulcer, diameter $20 \mathrm{~mm}$ ) ( $\mathbf{F i g . 1 , ~} \mathbf{\text { Fig. }}$ 2) that was subsequently closed as follows ( $\triangleright$ Video 1 ).

(1) A double-channel endoscope (GIF2TQ260M; Olympus) was inserted to visualize the mucosal defect in a straight view. (2) A Twin Grasper was inserted through the first channel and rotated.

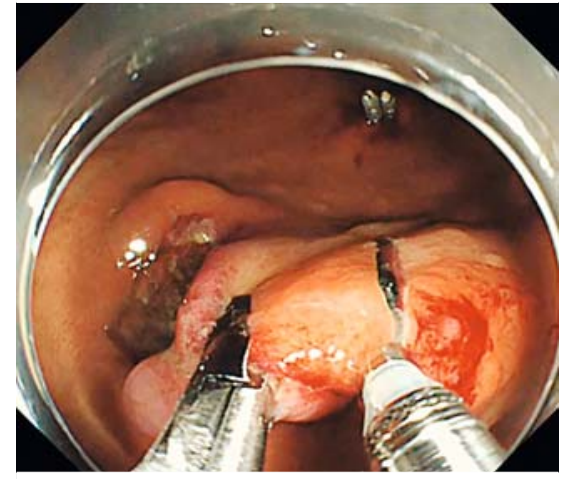
was drawn to pull both the grasped edges of the ulcer into the crotch of the EZ clip, and clip closure was performed.

One arm grasped the edge of the ulcer, then the other arm grasped opposite edge, and the two sides of the ulcer contacted completely ( $\triangleright$ Fig.3). (3) An EZ clip inserted through the second channel was rotated into an appropriate position and the sheath of the Twin Grasper was drawn to pull both of the grasped edges of the ulcer into the crotch of the clip,
Fig. 4 The sheath of the Twin Grasper 


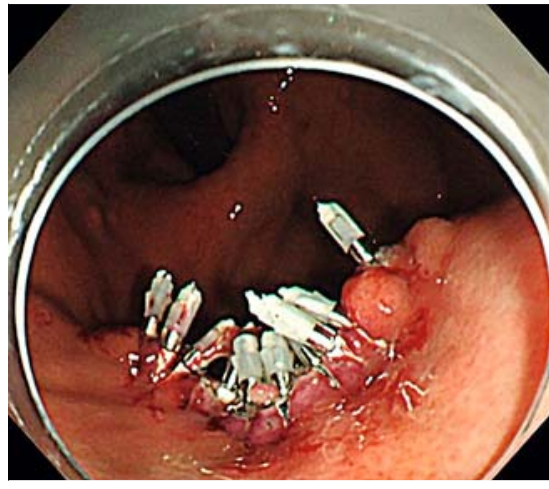

- Fig.5 Complete closure was performed in $11.7 \mathrm{~min}$.

where they were closed ( $\triangleright$ Fig.4). (4) These steps were repeated until the defect was completely closed (procedure duration $11.7 \mathrm{~min}$ ) ( $\vee$ Fig. 5). The patient was discharged 5 days after ESD without adverse events.

The advantage of the abovementioned Twin Grasper and EZ clip-based mucosal defect closure method is that the Twin Grasper enables the apposition of ulcer edges as though undertaken manually and facilitates defect closure under direct visualization. Therefore, this easy closure method will be one of the effective and safe options for closing a postESD artificial gastric ulcer.

Endoscopy_UCTN_Code_CPL_1AJ_2AD

\section{Competing interests}

The authors declare that they have no conflict of interest.
Michiko Nakaoka , Hideyuki Chiba $\odot$ Keiji Yamada, Naoya Okada, Jun Arimoto, Hiroki Kuwabara , Toru Goto

Department of Gastroenterology, Omori Red Cross Hospital, Chuo, Ota-Ku, Tokyo, Japan

\section{Corresponding author}

\section{Hideyuki Chiba, MD, PhD}

Department of Gastroenterology, Omori Red Cross Hospital, 4-30-1, Chuo, Ota-Ku, Tokyo, 143-0024, Japan

Fax: +81-3-3776-0004

h.chiba04@gmail.com

\section{References}

[1] Choi KD, Jung HY, Lee GH et al. Application of metal hemoclips for closure of endoscopic mucosal resection-induced ulcers of the stomach to prevent delayed bleeding. Surg Endosc 2008; 22: 1882-1886

[2] Shiotsuki K, Takizawa K, Notsu A et al. Endoloop closure following gastric endoscopic submucosal dissection to prevent delayed bleeding in patients receiving antithrombotic therapy. Scand J Gastroenterol 2021; 56: 1117-1125

[3] Kobara H, Mori H, Fujihara S et al. Outcomes of gastrointestinal defect closure with an over-the-scope clip system in a multicenter experience: An analysis of a successful suction method. World J Gastroenterol 2017; 23: 1645-1656

[4] Han S, Wani S, Edmundowicz SA. Feasibility of endoscopic suturing to prevent adverse events and hospitalization after endoscopic submucosal dissection. Endosc Int Open 2020; 8: 1212-1217
[5] Akimoto T, Goto O, Sasaki M et al. Endoscopic hand suturing for mucosal defect closure after gastric endoscopic submucosal dissection may reduce the risk of postoperative bleeding in patients receiving antithrombotic therapy. Dig Endosc 2021. doi: $10.1111 /$ den. 14045

Bibliography

Endoscopy 2022; 54: E600-E601

DOI 10.1055/a-1711-4091

ISSN 0013-726X

published online 21.12.2021

(C) 2021. Thieme. All rights reserved.

Georg Thieme Verlag KG, Rüdigerstraße 14, 70469 Stuttgart, Germany

\section{ENDOSCOPY E-VIDEOS}

https://eref.thieme.de/e-videos

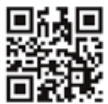

Endoscopy E-Videos is an open access online section, reporting on interesting cases and new techniques in gastroenterological endoscopy. All papers include a high quality video and all contributions are freely accessible online. Processing charges apply (currently EUR 375), discounts and wavers acc. to HINARI are available.

This section has its own submission website at https://mc.manuscriptcentral.com/e-videos 